Article type : Original Article

\title{
FLARES AFTER WITHDRAWAL OF BIOLOGIC THERAPIES IN JUVENILE IDIOPATHIC ARTHRITIS: CLINICAL AND LABORATORY CORRELATES OF REMISSION DURATION
}

Gabriele Simonini M.D.1, Giovanna Ferrara M.D.2, Irene Pontikaki M.D.3, Erika Scoccimarro M.D.4, Teresa Giani M.D.5, Andrea Taddio M.D.2,6, Pier Luigi Meroni M.D.3, Rolando Cimaz M.D.1

1 Anna Meyer Children Hospital and University of Florence, Italy; 2 University of Trieste, Italy; 3 Gaetano Pini Institute and University of Milano, Italy; 4 University of Florence, Italy; 5 Anna Meyer Children Hospital, Florence, Italy, 6 Institute of Maternal and child health IRCCS "Burlo Garofolo" Trieste, Italy

Subtitle: Risk of flare after withdrawing biologic therapies in JIA

Keywords: juvenile idiopathic arthritis, flare, biologic therapies, remission duration

Address correspondence to:

Rolando Cimaz, MD Anna Meyer Children Hospital and University of Florence, Italy tel +39055 5662924; email: rolando.cimaz@meyer.it

The authors declare no conflict of interest and received no financial support with regard to the work

This article has been accepted for publication and undergone full peer review but has not been through the copyediting, typesetting, pagination and proofreading process, which may lead to differences between this version and the Version of Record. Please cite this article as doi: 10.1002/acr.23435

This article is protected by copyright. All rights reserved. 


\begin{abstract}
Objective: to assess the time in remission after discontinuing biologic therapy in JIA patients.
\end{abstract}

Methods: we enrolled 135 patients followed in three tertiary care centers. Primary outcome was to assess, once remission was achieved, the time in remission up to the first flare after discontinuing treatment. Mann-Whitney U-test, Wilcoxon signed-rank test for paired samples, chi-square, and Fisher's exact test were used to compare data. Pearson and Spearman correlation tests were used to determine correlation coefficients for different variables. In order to identify predictors of outcome Cox regression model and Kaplan-Meier curves were constructed, each one at mean of entered covariates.

Results: The majority of enrolled patients flared after stopping treatment with biologics (102/135, 75.6\%) after a median follow-up time in remission off therapy of 6 months (range 3-109). A higher probability of maintaining remission after discontinuing treatment was present in systemic onset disease compared to the rest of JIA patients (Mantel-Cox $\left.\chi^{2} 8.31, \mathrm{p}<0.004\right)$. In analysis limited to JIA children with polyarticular and oligoarticular disease, patients who received biologics $>2$ years after achieving remission had a higher probability of maintaining such remission off therapy (18.64 \pm 3.3 months vs $11.51 \pm 2.7, \mathrm{p}<0.009$; Mantel-Cox $\chi 229.06, \mathrm{p}<0.002)$. No other clinical variable resulted significantly associated with a long-lasting remission.

Conclusion: Children with oligoarticular and polyarticular JIA who stop treatment before 2 years from remission have a higher chance of relapsing after biologic withdrawal.

\title{
Significance and Innovations
}

1) The majority of patients with juvenile idiopathic arthritis flared after stopping biologic therapy.

2) Patients with systemic JIA are less likely to flare after withdrawal of biologic therapy.

This article is protected by copyright. All rights reserved. 
3) Patients with oligoarticular and polyarticular JIA who stop treatment before 2 years from remission achievement have a higher chance of relapsing after biologic withdrawal.

\section{Introduction}

Juvenile idiopathic arthritis (JIA) is the most common rheumatic disease of childhood and includes a heterogeneous group of arthritis of unknown aetiology with onset before the age of 16 years that persist for $>6$ weeks (1). JIA is classified according to the revised ILAR criteria (2) into seven categories. The severity of disease and long-term outcome are variable between different JIA categories, and even within the same type, between different individuals. Studies have shown that at least one third of patients may require treatment into adulthood $(3,4)$. With modern treatment and especially biologic treatment, the objective of the management of JIA is to achieve inactive disease, which should persist for the longest period, and in current practice, this is obtained in a high percentage of cases overall, with the exception of RF-positive polyarthritis and systemic onset disease (5). Many patients discontinue antirheumatic treatment, but most of them experience a recurrence of disease. Since prolonged treatment of patients with inactive disease may result in unnecessary exposure to adverse effects, the identification of clinical features associated with an increased risk of recurrences would be helpful in driving the choice of duration therapy. While some information in this regard exist for second-line drugs (eg methotrexate), studies on biologic therapy are lacking.

The aim of our study was therefore to assess the remission duration after discontinuing biologic therapy in a retrospective multicenter cohort of patients with JIA, and to identify possible correlates with risk of subsequent flares.

\section{Materials and Methods}

We designed a multicentre, retrospective analysis of clinical chart data from three tertiary paediatric rheumatology centres in Italy (Anna Meyer Children Hospital - Florence, Gaetano Pini Institute Milano and Institute for Maternal and Child Health - IRCCS "Burlo Garofolo", Trieste).

This article is protected by copyright. All rights reserved. 


\section{Inclusion criteria}

To be considered eligible for this study, patients were required to have, at the time of enrolment: 1) JIA diagnosis according to ILAR criteria $(2) ; 2$ ) inactive disease after a first cycle of any biologic treatment, single or in combination therapy, for at least 6 months; 3) discontinued all treatments (including DMARDs) for at least 3 months; 4) age at the time of biologic treatment onset $<18$ years, since we aimed to provide data limited to the paediatric age.

\section{Main outcome measures}

The primary outcome of this study was to assess, once remission on medication was achieved, the time to the first relapse after discontinuing treatment. In addition, secondary outcomes were, once biologic drug was started, time to achieve disease remission on medication, time to biologic discontinuation, time in remission on medication before discontinuing all treatments. Clinical and laboratory correlates of remission duration were evaluated.

Clinical remission on medication was defined as a persistent inactive disease for a minimum of 6 continuous months as for Wallace criteria (6). Inactive disease was defined as:

1) absence of joints with active arthritis,

2) absence of systemic manifestations (fever, rash, serositis, splenomegaly or generalized lymphadenopathy attributable to JIA-systemic onset),

3) absence of active uveitis,

4) absence of enthesitis (for ERA),

5) normal ESR or CRP

6) and, in any case, if PGA indicates no disease activity (VAS=0)

A modification of the more recent Wallace criteria for inactive disease (7) was introduced since we did not consider the morning stiffness as a criteria, considering it too vague. A flare was considered 
when there was loss of at least two of the previous criteria and, in any case, when the treating physicians decided treatment intensification due to a significant flare (5).

\section{Analysis plan}

Chart review has been performed between September 2015 and March 2016. Data extracted from clinical charts included: demographic variables, JIA category, laboratory parameters of inflammation and antinuclear antibody positivity (titer $>$ or $=1: 160$, in two consecutive collections), number of active joints at start of biologic drug, associated uveitis, corticosteroid concomitant and previous usage, DMARDs concomitant and previous usage, type of biologic administered, time interval between diagnosis and the initiation of biologic therapy, time to achieve remission once biologic drug was started, time in remission on therapy before discontinuing all treatments, cumulative time on biologic, time in remission off therapy, therapeutic decision upon flare and follow up time.

Since anonymized data were used and the study was retrospective, according to national regulations no ethics committee approval was required.

\section{Statistical analysis}

All results are expressed as mean \pm S.D or median, range. Mann-Whitney U-test, Wilcoxon signedrank test for paired samples, chi-square tests, and Fisher's exact test, when appropriate, were used to compare data. An a priori power analysis was completed using G Power program (8). Two-tailed p values were employed. Considering the epidemiology of JIA a large expected difference was estimated for the sample: the effect size $f=0.40$, as per Cohen (9). In addition, power was set at 0.95 , meaning there would be a $95 \%$ probability of reaching statistical significance if the obtained differences were truly present in the population. Results from the power analysis showed that 120 participants would be required.

The following data, entered into a customized JIA database, were considered as variables for correlations, and as covariates for the survival curves: age at study entry, age at initiation of biologic therapy, gender, associated uveitis, disease duration, age at JIA onset, active arthritis duration, time 
interval between disease onset and initiation of biologic drug, type of therapy administration (number and frequency), concomitant medications, previous cumulative corticosteroid dose and its duration, previous DMARD treatment duration, number of previous flares, ANA presence, time to obtain remission, time in remission on therapy, time in remission without therapy, cumulative time on therapy, and follow-up time. Before each eligible subject was recruited, an inclusion criteria second revision has been performed by the Florence centre, who acted as study coordinator and data management. Pearson and Spearman correlation tests were used to determine correlation coefficients for different variables. In order to identify predictors of outcome Cox regression model and KaplanMeier curves were constructed, each one at mean of the above reported covariates. Non-parametric tests were used, where necessary, due to the small size of our groups and to the skewness of our data. Levels of $\mathrm{p}<0.05$ were considered statistically significant. All analyses were performed on SPSS package for MAC, version 23.0 (SPSS, Inc., Chicago, IL, USA).

\section{Results}

Among 349 patients followed for JIA at the three tertiary care centers, between January 2000 and March 2016, and treated with biologics started before 18 years of age, 135 (38.6\%, 104 female, 31 male, median age 14.6 years, range 3.2-16.8) resulted eligible, since they achieved clinical remission on therapy for at least 6 months and could discontinue biologic treatment.

Clinical characteristics of enrolled patients are reported in Table 1. Eighty-seven patients had received Etanercept, 27 Adalimumab, 12 Infliximab, 7 Anakinra, 1 Rituximab, and 1 Abatacept, each one administered at the current standard dose for JIA, for a median period of 20 months (range, 7-146). Ninety-two (68.1\%) children also received concomitant administration of MTX treatment at standard dose $10-15 \mathrm{mg} / \mathrm{m}^{2} 7$ week.

The vast majority of enrolled patients flared after stopping treatment with biologics $(102 / 135,75.6 \%)$ with a median follow-up time in remission off therapy of 6 months (range 3-109). Among patients who flared, $34.1 \%$ restarted the same biologic, $19.3 \%$ switched to another biologic, $4.4 \%$ restarted

This article is protected by copyright. All rights reserved. 
methotrexate, $11.9 \%$ underwent intra-articular corticosteroid injection, $2.2 \%$ did not receive any treatment, $0.7 \%$ received another anti-rheumatic medication.

Considering the time point one year after treatment discontinuation $42 / 135(31.1 \%)$ patients were still in remission [Figure 1]. For patients who were still in remission after discontinuation, remission lasted for a median period of 53 months (range 12-109): 17/48 with polyarticular onset, 7/27 oligoarticular extended, 6/35 oligoarticular persistent, 2/6 enthesitis-related arthritis, 2/7 psoriatic arthritis, and 8/12 systemic onset JIA. Stratifying by JIA categories, Kaplan-Meier curves showed an overall difference among different types of JIA (Mantel-Cox $\chi^{2} 12.47, \mathrm{p}<0.02$ ), with systemic onset disease showing a higher probability of maintaining clinical remission off therapy when compared to the rest of JIA patients (Mantel-Cox $\left.\chi^{2} 8.31, \mathrm{p}<0.004\right)$ [Figure 2].

Due to the non homogeneous distribution across JIA categories in our enrolled population, and the known different genetic backgrounds and response to therapy among them, in order to identify potential correlates with the main outcome we limited analysis to 106 children with polyarticular and oligoarticular disease, thus excluding systemic JIA, RF-positive, enthesitis-related arthritis and psoriatic categories.

In this analysis ANA positivity was not associated with a higher probability of flare (Mantel-Cox $\chi^{2}$ $0.08, \mathrm{p}=.77)$. Children who received biologic therapy for more than 2 years after achieving remission, thus a clinical remission on therapy longer than 2 years, had a higher probability of maintaining clinical remission off therapy compared to children who received biologic therapy for less than 2 years after achieving remission (Mantel-Cox $\chi^{2}$ 9.06, $\mathrm{p}<0.002$ ) [Figure 3] and mean time on clinical remission off therapy resulted significantly higher $(18.64 \pm 3.3$ months $v s 11.51 \pm 2.7, \mathrm{p}<0.009)$. Stratifying by 2 years of biologic treatment duration, once achieved remission, $14(87.5 \%)$ of 16 children were still on remission after treatment discontinuation compared to 2 (12.5\%) of 16 children; whilst $36(40 \%)$ of 90 children compared to $54(60 \%)$ of 90 flared again after treatment discontinuation (Mantel-Haenszel $\chi^{2} 10.36, \mathrm{p}<0.001$ ) [Figure 4].

This article is protected by copyright. All rights reserved. 
Conversely, our analysis failed to identify other time durations such as 6,12 and 18 months of clinical remission on therapy as predictors of flare.

No other variable, including total length of treatment, type of biologic treatment and concomitant administration of MTX, resulted significantly predictors of long-lasting remission without therapy.

\section{Discussion}

In the last two decades, novel therapies, and especially the TNF-blocking agents, have improved the remission rate in JIA, with the majority of patients achieving clinical remission and many discontinuing therapies.

In our study, we found that $37.8 \%$ of patients affected by JIA discontinued biologic drug for persistent inactive disease, after a median of 20 months from biologic onset, but that most of them relapsed. Guzman et al (5) reported that the probability of discontinuing all medications was $43 \%$, which is similar to what we found in the present study.

Despite achieving clinical remission, we found that most children with JIA flared after discontinuing therapy. However, this is hardly surprising, since it has already known that neither MTX nor biologic therapies for JIA normalize immune function (10).

To our knowledge, our one is one of the few studies to deal with the probability of flares after stopping therapy. A prospective French study (AJIBIOREM, clinicaltrials.gov NCT02840175) has been planned but not yet recruiting. The study will investigate if the early tapering and then withdrawal of biological agent, in a homogenous group of children with juvenile idiopathic arthritis achieving inactive disease, is safe and not inferior to the maintenance of stable treatment intensity over 24 weeks. Even if retrospective, our study seems to underscore that stopping biologics after achieving remission before two years of continued treatment might be a risk for JIA children to a higher chance of relapse: patients in remission for $>2$ years on biologics were likely to sustain remission longer than those with $<2$ years of remission. The caveat in our case is that the comparison

This article is protected by copyright. All rights reserved. 
arms were not randomized, so the group that successfully sustain 2 years of remission may represent an intrinsically better-prognosis group. Foell et al. (11) reported a probability of flare within 12 months of stopping therapy of $39.6 \%$, similar to that of Guzman et al. (12) of $31.7 \%$. In our study one year after therapy discontinuation, only $31.9 \%$ of patients were still in remission, so the probability of flare is higher then previous reported but similar to that of Chang et al. (63\%) (13). This difference could be explained with differences in diagnostic criteria of flare and in treatment attitudes across studies. In fact, we used for the definition of inactive disease a PGA of 0 , and not $<10$ as Guzman, and also requested normal levels of acute phase reactants, differently from Guzman. The use of biologic drugs, and consequently a more severe disease, could explain the difference with the results of Foell, who analysed only patients treated with methotrexate.

In our study, among different JIA categories, children with systemic JIA had the lowest probability of flares, compared to the other categories, particularly polyarticular or extended oligoarticular groups. Among patients affected by systemic JIA who flared, most were older patients who received TNFblocking agents, that are known to be less effective in this disease compared with other JIA categories. In addition, it is known that systemic JIA encompasses different genetic background and response to therapy from the other JIA categories (1).

Guzman et al. (12) recently analysed risk factors for flare after stopping biologic therapy, finding that children with RF-positive polyarthritis had the highest probability of flare and children with systemic JIA the lowest. The prognosis of systemic JIA differs among studies $(14,15)$; this is important with regard to our results since the natural history of the disease can be a confounding factor in that spontaneous remission can occur in a substantial percentage of patients. However, our results seem in accordance with Guzman, despite the low number of RF-positive and the relatively high number of polyarticular and extended oligoarticular patients in our cohort.

This article is protected by copyright. All rights reserved. 
Iglesias et al. (16) in a cohort of non-systemic JIA found no relationship between JIA type and ANA positivity with the percentage of relapse after TNF-blocking discontinuation. Our analysis, not including systemic JIA as well RF, ERA and psoriatic children showed similar results: ANA positivity was not associated with a higher probability of flare.

The design of our study did not have the chance to consider potential biomarkers related to a higher risk of flare. In previous studies Anink et al. (17) found that patients who flared within 6 months after discontinuation of etanercept had higher myeloid related protein (MRP8/14) levels at the time of discontinuation, compared to patients who did not have flares. Similar result had already been obtained by Foell et al. (11) who in a randomized clinical trial proved the safety of withdrawing methotrexate therapy after 6 (versus 12) months of stable remission. In addition to MRP8/14, also the phagocyte activation markers S100A12, has been identified as a predictive biomarker for the risk of a flare in a recent study of PRINTO group (18).

Chang et al. (13) in a retrospective monocentric study involving patients with RF-positive and negative polyarthritis and ERA, recently found that patients who withdrew anti-TNF and continued MTX flared more than those who stopped MTX and continued anti-TNF (89 vs 12\%). We found no difference in patients treated with biologic in combination with or without MTX with regard to disease flares.

Our study, being a retrospective and multicentre chart review, has of course some limitations, eg the choice of starting biologic drug is not standardized across centres, the treatment plans and decisions to withdraw drug can result heterogeneous, and the JADAS was not available for all patients.

However, the definition of flare was standardized and quite strict, as inclusion criteria to be enrolled and the follow-up schedule is the same in the three clinics. On the other hand, as far as we now, shared guidelines regarding treatment withdrawal are not yet available, thus limiting the chance to make homogeneous treatment decision in this setting across centres, mostly in a retrospective collection.

This article is protected by copyright. All rights reserved. 
Furthermore, since the number of patients in certain JIA subtypes was too small to draw reliable conclusions, in order to identify potential clinical descriptor of relapse after stopping biologic treatment, we limited the analysis to the more homogenous groups with an equal distribution of ANA positivity across them.

Another potential limitation of our study might be the exclusion from the eligible population of children with more than one biologic treatment cycle before achieving remission, thus potentially excluding children with a more refractory disease. We acknowledge this limitation; however, from a statistical point of view, in order to minimize sample bias and make as much possible homogenous comparisons in an heterogeneous population such as JIA, we attempted to compare JIA children with similar clinical disease history. In order to identify clinical predictor of relapse, several time variables, e.g. active disease duration, and time interval between disease onset and initiation of biologic drug, acted as covariates for calculating survival curves thus limiting their effect size on target outcome.

In conclusion, even if in a retrospective study, we showed that patients with systemic onset disease are less likely to flare when compared to other categories, and that JIA children belonging to oligoarticular and polyarticular groups who stop treatment before two years of remission have a higher chance of relapsing after biologic withdrawal. These data seem to suggest that biologic treatment, in selected JIA categories, might be continued for at least 2 years after achieving clinical remission.

\section{Acknowledgements}

None.

This article is protected by copyright. All rights reserved. 


\section{References}

1. Ravelli A, Martini A. Juvenile idiopathic arthritis. Lancet 2007; 369:767-78

2. Petty RE, Southwood TR, Manners P, Baum J, Glass DN, Goldenberg J et al. International League of Associations for Rheumatology classification of juvenile idiopathic arthritis: second revision, Edmonton 2001. J Rheumatol 2004; 31:390-2

3. Minden K, Kiessling U, Listing J, Niewerth M, Doring E, Meincke J, et al. Prognosis of patients with juvenile chronic arthritis and juvenile spondyloarthropathy. J Rheumatol 2000;27:2256-63.

4. Bertilsson L, Andersson-Gare B, Fasth A, Petersson IF, Forsblad-D'elia H. Disease course, outcome, and predictors of outcome in a population-based juvenile chronic arthritis cohort followed for 17 years. J Rheumatol 2013;40:715-24.

5. Guzman J, Oen K, Tucker LB, Huber AM, Shiff N, Boire G et al. For the ReACCh-Out investigators. The outcomes of juvenile idiopathic arthritis in children managed with contemporary treatments: results from the ReACCh-Out cohort. Ann Rheum Dis $2015 ; 74: 1854-60$

6. Wallace CA, Ruperto N, Giannini E, Childhood Arthritis and Rheumatology Research Alliance; Pediatric Rheumatology International Trials Organization; Pediatric Rheumatology Collaborative Study Group. Preliminary criteria for clinical remission for select categories of juvenile idiopathic arthritis. J Rheumatol. 2004;31:2290-4.

7. Wallace CA, Giannini EH, Huang B for the CARRA, PRINTO and PRCSG. American College of Rheumatology provisional criteria for defining clinical inactive disease in select categories of juvenile idiopathic arthritis. Arthritis Care Res (Hoboken). 2011;63:929-36

8. Erdfelder, E, Faul, F, Buchner, A. GPOWER: A general power analysis program. Behavior Research Methods, Instruments, \& Computers, 1996; 28, 1-11.

9. Cohen J. Statistical power analysis for the behavioural sciences. 2nd ed. Hillsdale (NJ): Lawrence Erlbaum Associates; 1988.1617

This article is protected by copyright. All rights reserved. 
10. Jiang K, Frank M, Chen Y, Osban J, Jarvis JN. Genomic characterization of remission in juvenile idiopathic arthritis. Arthritis Res Ther. 2013 Aug 30;15(4):R100

11. Foell D, Wulffraat N, Wedderburn LR, Wittkowski H, Frosch M, Gerss J et al. Methotrexate withdrawal at 6 vs 12 months in juvenile idiopathic arthritis in remission: a randomized clinical trial. JAMA. 2010;303:1266-73

12. Guzman J, Oen K, Huber AM, Watanabe Duffy K, Boire G, Shiff N et al. The risk and nature of flares in juvenile idiopathic arthritis: results from the ReACCh-Out cohort. Ann Rheum Dis 2016;75:1092-1098

13. Chang CY, Meyer RM, Reiff AO. Impact of medication withdrawal method on flare-free survival in patients with juvenile idiopathic arthritis on combination therapy. Arthritis Care Res (Hoboken). 2015;67:658-66

14. Cimaz R. Systemic-onset juvenile idiopathic arthritis. Autoimmun Rev. 2016;15:931-4

15. Singh-Grewal D, Schneider R, Bayer N, Feldman BM. Predictors of disease course and remission in systemic juvenile idiopathic arthritis: significance of early clinical and laboratory features. Arthritis Rheum 2006;54:1595-601

16. Iglesias E1, Torrente-Segarra V, Bou R, Ricart S, González MI, Sánchez J et al. Nonsystemic juvenile idiopathic arthritis outcome after reaching clinical remission with anti-TNF$\alpha$ therapy: a clinical practice observational study of patients who discontinued treatment. Rheumatol Int. 2014;34:1053-7

17. Anink J, Van Suijlekom-Smit LW, Otten MH, Prince FH, van Rossum MA, Dolman KM et al. MRP8/14 serum levels as a predictor of response to starting and stopping anti-TNF treatment in juvenile idiopathic arthritis. Arthritis Res Ther. 2015;17:200

18. Gerss J, Roth J, Holzinger D, Ruperto N, Wittkowski H, Frosch M et al. Phagocyte-specific S100 proteins and high-sensitivity $\mathrm{C}$ reactive protein as biomarkers for a risk-adapted treatment to maintain remission in juvenile idiopathic arthritis: a comparative study. Ann Rheum Dis. 2012;71:1991-7

This article is protected by copyright. All rights reserved. 


\section{Figure Legends}

Figure 1: Kaplan-Meier curve showing the time up to the first relapse after discontinuing therapy among enrolled patients.

Figure 2: Kaplan-Meier curves showing the difference in the time up to the first relapse after discontinuing therapy according to JIA categories.

Figure 3: Kaplan-Meier curves showing the difference in the time up to the first relapse after discontinuing therapy according to the duration of therapy $(<$ or $>2$ years) after achieving remission.

Figure 4. Figure shows number and percentage of children on remission after treatment discontinuation compared to children who flared after treatment discontinuation, stratified by 2 years of biologic treatment (Mantel-Haenszel $\chi^{2} 10.36, \mathrm{p}<0.001$ ) 


\begin{tabular}{|c|c|c|c|c|c|c|c|c|}
\hline & Poly RF- & Poly RF + & Oly-Pers & Oly- ext & systemic & ERA & Psoriatic & Total \\
\hline $\mathrm{N}^{\circ}$ ptients (n, \%) & $44(32.6 \%)$ & $4(3 \%)$ & $35(25.9 \%)$ & $27(20 \%)$ & $12(8 \%)$ & $6(4.4 \%)$ & $7(5.2 \%)$ & 135 \\
\hline Female $(\mathrm{n}, \%)$ & $35(79 \%)$ & $3(75 \%)$ & $29(83 \%)$ & $20(74 \%)$ & $8(66 \%)$ & $3(50 \%)$ & $6(86 \%)$ & 104 \\
\hline $\begin{array}{l}\text { Age at onset, years } \\
\text { (median, range) }\end{array}$ & $\begin{array}{l}6 \\
1-14\end{array}$ & $\begin{array}{l}11.5 \\
7-16\end{array}$ & $\begin{array}{l}2 \\
1-13\end{array}$ & $\begin{array}{l}3 \\
11-14\end{array}$ & $\begin{array}{l}4 \\
0.9-14\end{array}$ & $\begin{array}{l}9 \\
7-14\end{array}$ & $\begin{array}{l}3 \\
1-10\end{array}$ & $\begin{array}{l}4 \\
0.9-16\end{array}$ \\
\hline $\begin{array}{l}\text { Age at starting biologic } \\
\text { (mean years } \mathrm{SD} \text { ) }\end{array}$ & $9.45 \pm 4.72$ & $12 \pm 4.68$ & $8.03 \pm 4.42$ & $9.41 \pm 4.71$ & $8.25 \pm 6.01$ & $\begin{array}{r}11.33 \\
\pm 3.67\end{array}$ & $\begin{array}{l}6.57 \\
\pm 2.57\end{array}$ & $\begin{array}{l}8.98 \\
\pm 4.68\end{array}$ \\
\hline $\begin{array}{l}\mathrm{N}^{\circ} \text { active joints at } \\
\text { starting } \quad \text { biologic } \\
\text { (median, range) }\end{array}$ & $\begin{array}{l}7 \\
1-18\end{array}$ & $\begin{array}{l}7.5 \\
1-19\end{array}$ & $\begin{array}{l}6 \\
1-14\end{array}$ & $\begin{array}{l}2 \\
0-13\end{array}$ & $\begin{array}{l}7 \\
1-19\end{array}$ & $\begin{array}{l}2 \\
1-10\end{array}$ & $\begin{array}{l}5 \\
1-10\end{array}$ & $\begin{array}{l}5 \\
0-19\end{array}$ \\
\hline Etanercept & 36 & 2 & 18 & 23 & 2 & 1 & 5 & 87 \\
\hline Adalimumab & 4 & 0 & 14 & 3 & 0 & 5 & 5 & 27 \\
\hline Infliximab & 3 & 1 & 3 & 1 & 3 & 0 & 5 & 12 \\
\hline Anakinra & 0 & 0 & 0 & 0 & 7 & 0 & 0 & 7 \\
\hline Rituximab & 1 & 0 & 0 & 0 & 0 & 0 & 0 & 1 \\
\hline Abatacept & 0 & 1 & 0 & 0 & 0 & 0 & 0 & 1 \\
\hline $\begin{array}{l}\text { Follow up time on } \\
\text { remission on therapy, } \\
\text { months (median, range) }\end{array}$ & $\begin{array}{l}23.5 \\
(6-109)\end{array}$ & $\begin{array}{l}25.5 \\
(24-61)\end{array}$ & $\begin{array}{l}22 \\
(7-86)\end{array}$ & $\begin{array}{l}16 \\
(8-77)\end{array}$ & $\begin{array}{l}18 \\
(7-86)\end{array}$ & $\begin{array}{l}11 \\
(6-37)\end{array}$ & $\begin{array}{l}24 \\
(9-36)\end{array}$ & $\begin{array}{l}22 \\
(6-109)\end{array}$ \\
\hline $\begin{array}{l}\text { Follow up time on } \\
\text { remission out of therapy } \\
\text { months (median, range) }\end{array}$ & $\begin{array}{l}6 \\
(3-92)\end{array}$ & $\begin{array}{l}60 \\
(13-89)\end{array}$ & $\begin{array}{l}6 \\
(3-75)\end{array}$ & $\begin{array}{l}4 \\
(5-109)\end{array}$ & $\begin{array}{l}15.5 \\
(7-93)\end{array}$ & $\begin{array}{l}7.5 \\
(3-50)\end{array}$ & $\begin{array}{l}7 \\
(4-32)\end{array}$ & $\begin{array}{l}6 \\
(3-109)\end{array}$ \\
\hline
\end{tabular}

This article is protected by copyright. All rights reserved. 


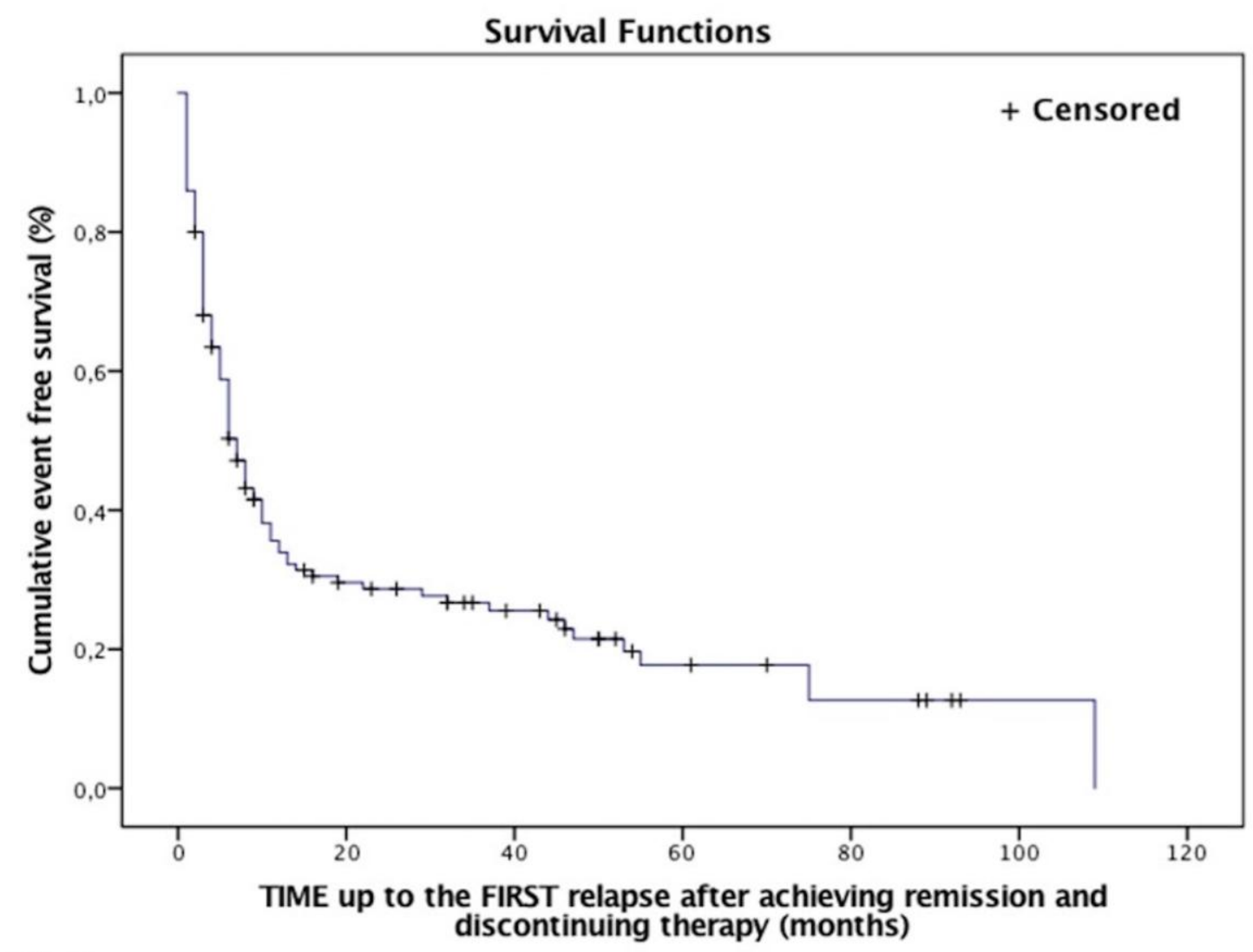

$\mathrm{N}^{\circ}$ of

subjects 135

32

21

9

5

1

0

This article is protected by copyright. All rights reserved. 


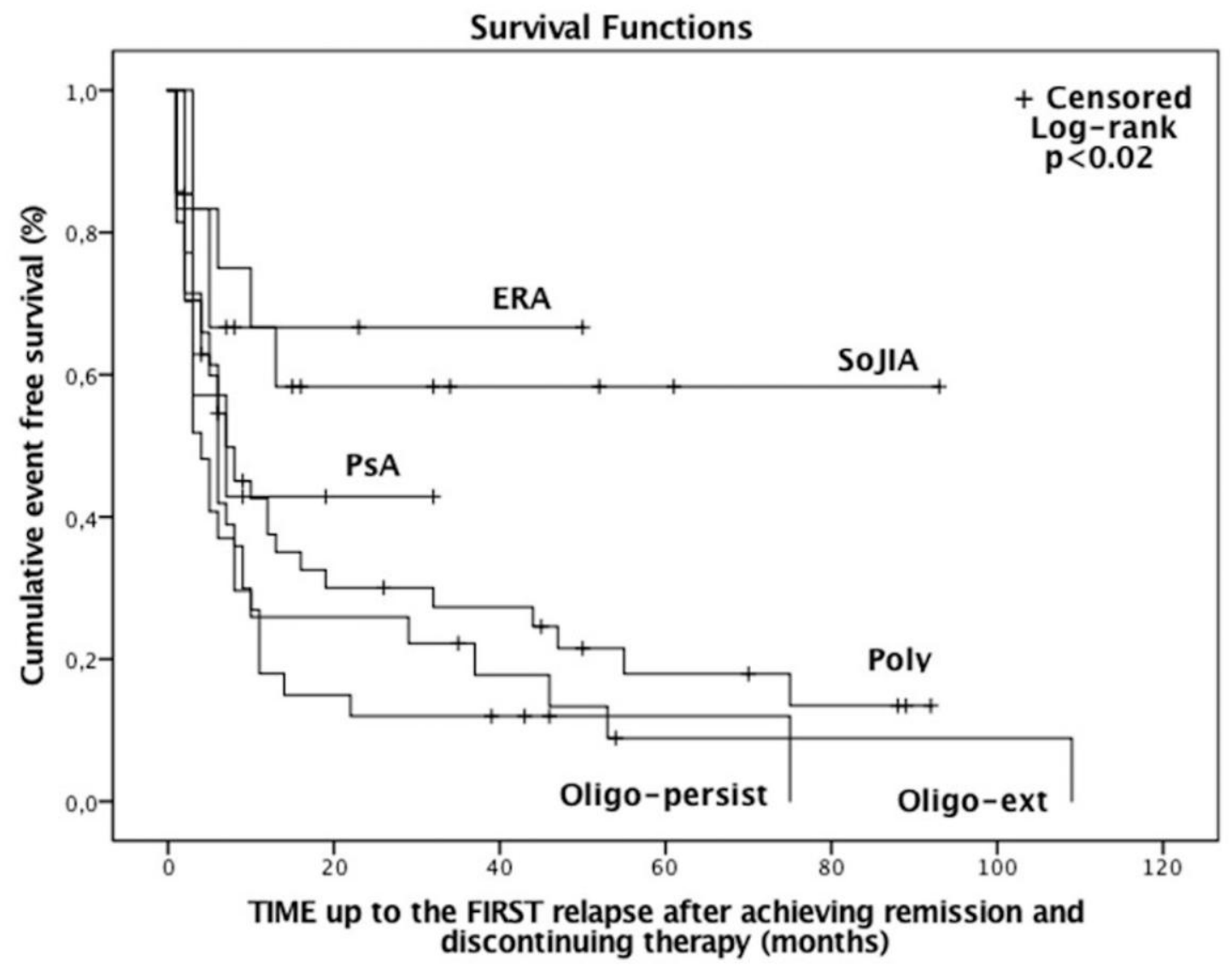

This article is protected by copyright. All rights reserved. 
Survival Functions

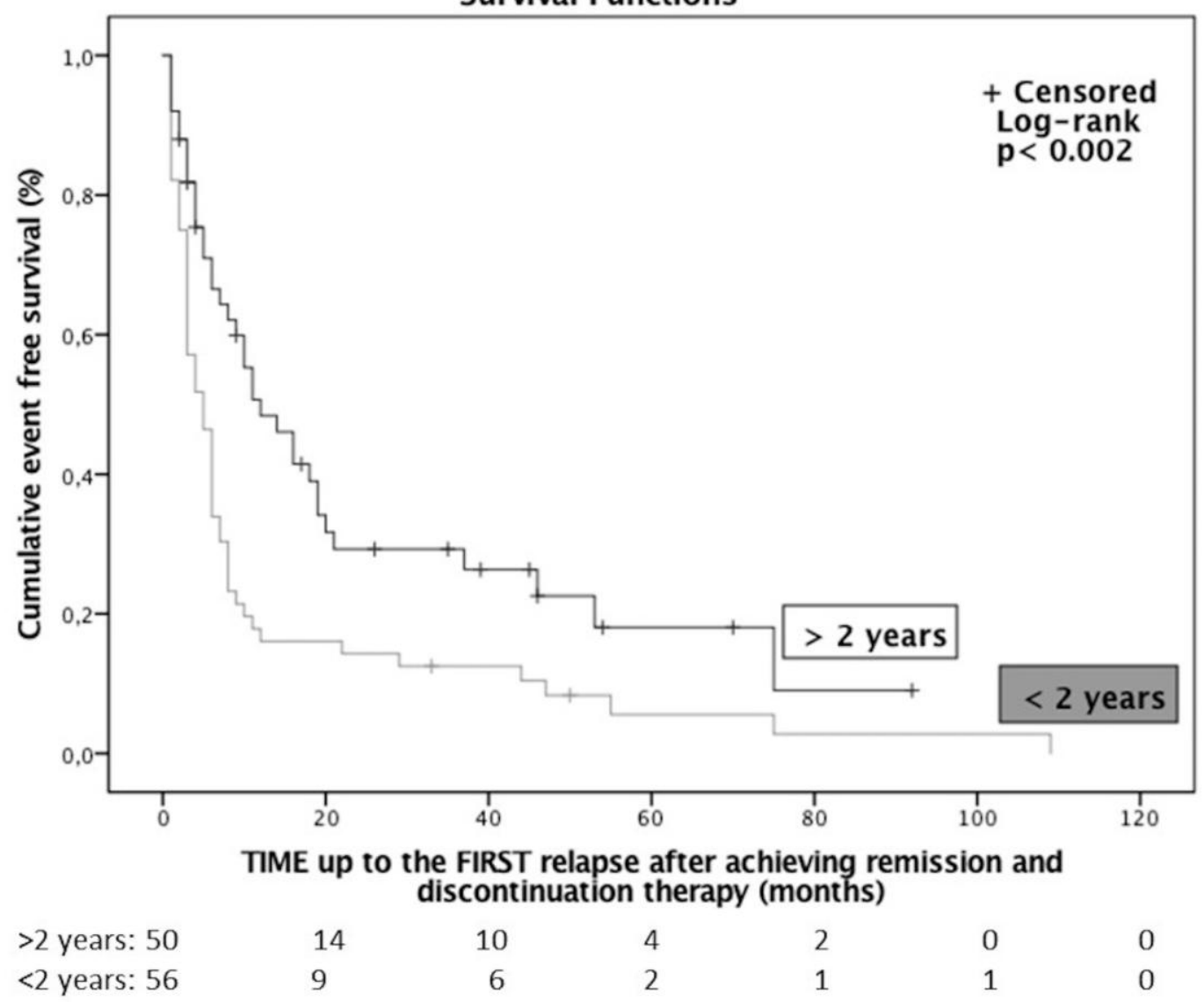

This article is protected by copyright. All rights reserved. 


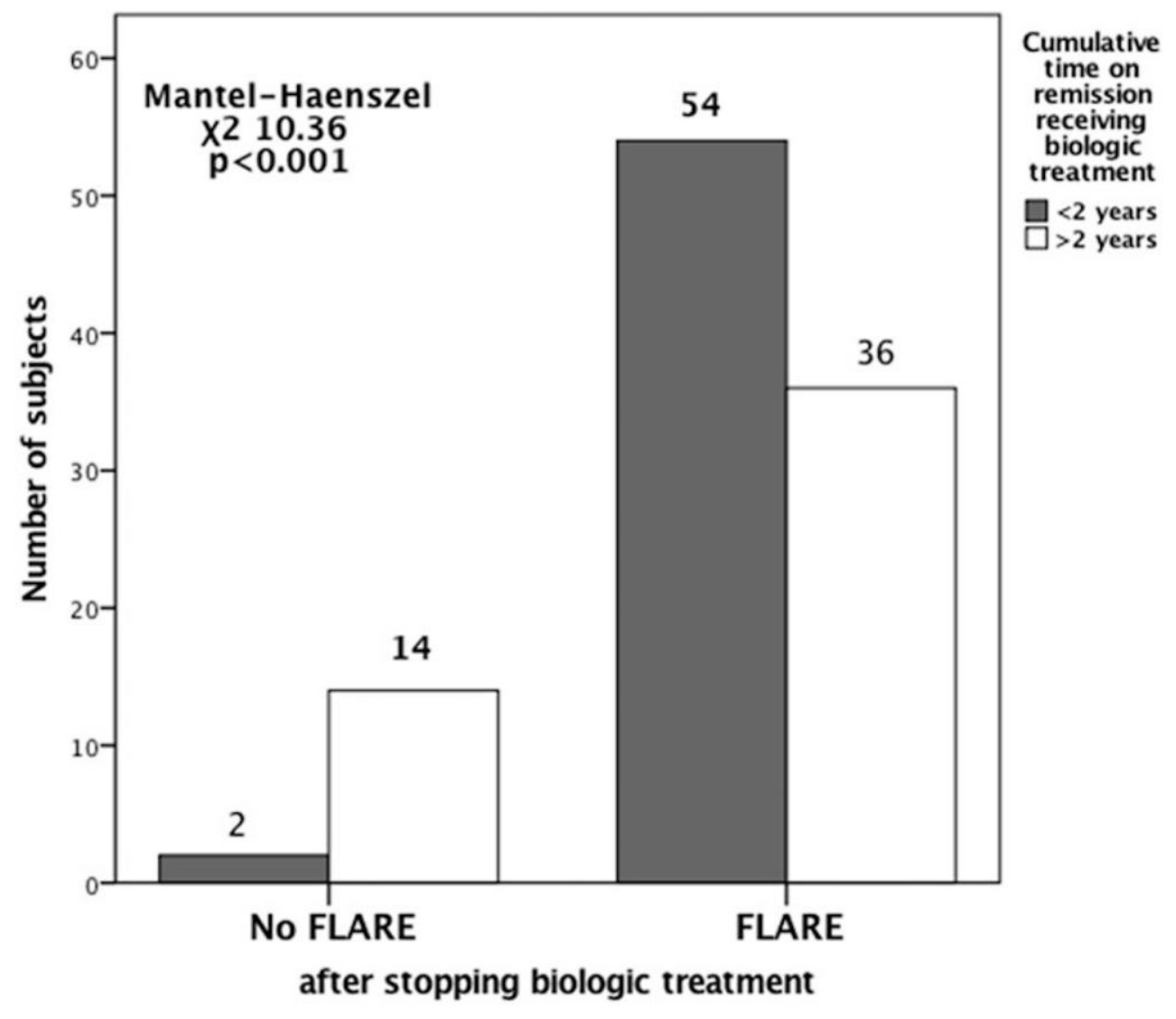

This article is protected by copyright. All rights reserved. 